\title{
Familial Lupus and Clinical Characteristics in Saudi Arabia
}

\author{
Jamal Abdullah Albishri*, Samar Saad Alshehri, Alwalaa Mohammed Altowairqi, \\ Reem Magboul Aljuaid \\ Taif University, Taif, Saudi Arabia \\ Email: *Jbeshri@gmail.com, Alshehri.samar.saad@gmail.com,Dr.lulu2017@gmail.com, \\ Dr.re1em000@gmail.com
}

Received 13 November 2015; accepted 5 December 2015; published 8 December 2015

Copyright (C) 2015 by authors and Scientific Research Publishing Inc.

This work is licensed under the Creative Commons Attribution International License (CC BY). http://creativecommons.org/licenses/by/4.0/

(c) (i) Open Access

\begin{abstract}
Background: It has been proven that a family history of systemic lupus erythematosus (SLE) is a risk factor for the development of the disease, and the risk increases with increasing number of relatives affected. In Saudi Arabia, high consanguinity rate leads to higher incidence of familial form than in other countries. We compare the percentage of familial versus sporadic SLE among Saudi patients. The second aim of the present study is to compare clinical characteristics between the two forms of the disease. Methods: This cross-sectional study includes 47 female patients whom are selected and investigated through three phases. We have added additional two categories of relatives, based on unconventional definition. We have examined and compared demographic characteristics of the patients with familial and sporadic SLE. We have also compared the percentage of familial vs. sporadic lupus and clinical characteristics of the two forms. Results: All the patients are females, aged between 18 and 43 years. The highest percentage of patients resides in the central region of Saudi Arabia (34\%). The origin of the big family or tribe also most commonly occurs in the central region (34\%). Data analysis results in $27.7 \%$ of patients with familial form of SLE. Sporadic form is found in $72.3 \%$ of patients. Consanguinity between patients' parents is noticed in both familial form $(61.5 \%)$ and sporadic form $(58.8 \%)$. Clinical manifestations are similar between patients with familial and sporadic form. Conclusion: Our results show a high percentage of familial lupus among Saudi patients. More research is required in order to estimate the inheritance pattern of familial SLE and involvement of genetic and environmental factors.
\end{abstract}

\section{Keywords}

SLE, Lupus, Familial, Saudi Arabia, Genetics

\footnotetext{
${ }^{*}$ Corresponding author.
} 


\section{Introduction}

Investigation of epidemiological features of systemic lupus erythematosus (SLE) has always been a great challenge. Giving that SLE has a broad spectrum of clinical modalities and variable immunological profiles, the definition of the disease, classification criteria, as well as epidemiological study approaches change frequently over time [1].

Addressing the prevalence of SLE in the population of Saudi Arabia is a controversial topic, mainly due to lack of scientific evidence. A study conducted in Al-Qaseem region of Saudi Arabia showed prevalence of SLE of 19.28 per 100,000 people [2]. There were studies showing both higher [3] and lower [4] prevalence of SLE in Saudi Arabia compared to developed countries.

Epidemiological data have shown substantial influence of genetic factors on the development of SLE [5]. It has been proven that family history of SLE is a risk factor for the development of the disease, and the risk increases with increasing number of relatives affected [6]. The results from studies conducted in different countries show that $4 \%$ - 11\% of SLE patients have at least one first-degree relative affected [7]. Majority of SLE patients still have sporadic form of the disease.

In Saudi Arabia, due to specific demographic profiles and cultural characteristics, genetic factors may have a much higher influence, resulting in higher incidence of familial form of SLE than in other countries. During the history, the majority of the population is organized in tribal manner based on a particular bloodline. Up until the second half of the 20th century, marriage between different classes was not normally considered, and endogamy was very pronounced [8]. This can indicate the cause of high incidence of consanguinity among the Saudi Arabian population, which is confirmed in one study conducted among 3212 Saudi families [9]. Based on the study results, they classify Saudi Arabia among countries with high rate of consanguinity. Therefore, Saudi Arabia has a high prevalence of autosomal and $\mathrm{X}$ linked recessive disorders.

As the genetics of SLE is still poorly investigated, the comparison of prevalence of sporadic and familial form of the disease in the population of specifically Saudi Arabia can open a new era of understanding of the genetic background in the development of the disease.

In this study, we compare the percentage of familial versus sporadic lupus among Saudi patients, and interpret the results considering specific demographic characteristics of the Saudi population. The second aim of the present study is to compare the clinical characteristics between the two forms of the disease.

\section{Methods}

The patients were first contacted via a group called "The Red Butterfly" created by one patient with SLE, on the WhatsApp social platform. The group was initiated in May 2014 and it has attracted a significant number of Arabic female patients via social networks, such as Facebook, Twitter, and Instagram. The group was founded for social and educational purposes. We were invited to become members of the group and we proposed other members to participate in this cross-sectional study in February 2015.

Each member of the group was communicated through three phases: WhatsApp phase, phone communication phase, and email phase. WhatsApp platform was used to initially contact each member of the group in order to get their agreement to participate in the phone communication phase. Phone communication phase was arranged using special format which consisted of: 1) the initial consent section which was done over the phone and documented; 2) general medical history; 3) extensive family history focused on occurrence of lupus among their relatives. During the email phase, each patient was asked to provide their medical report which confirms the diagnosis of SLE based on 1982 American College of Rheumatology (ACR) criteria. They all had informed consent to participate in the study. Both medical report and informed consent were sent in the form of scanned documents.

Of 71 patients, 14 were excluded for not being of Saudi nationality, 8 did not provide medical reports, and two did not answer phone calls, resulting in total of 47 patients who were included in the study.

In order to define the terms: first, second, and third degree relative, we used the definition of National Genetics and Genomics (NHS) [10]. First degree relative is considered a parent, sibling, or a child. A first degree relative shares approximately half of their genes with the person. A second degree relative is an uncle, aunt, nephew, niece, grandparent, grandchild or half-sibling. A second degree relative shares about one quarter of their genes with the person. A third degree relative is a first cousin, great-grandparent or great-grandchild. A third degree relative shares about one eighth of their genes with the person. Familial lupus was diagnosed with at least 2 rela- 
tives (1st, 2nd, or 3rd degree) with SLE.

We added an additional two categories of relatives, they don't meet the definition of National Genetics and Genomics (NHS) but they stem from the same tribe. For these family members, the number of genes they share with the patient is uncertain. A fourth degree relative does not meet the above criteria for first, second, and third degree relatives, but claim that they descend from the same great-great grand-father (Fakith or the small family). Fifth grade family members claim that they descend from one of the two eponyms Arab ancestor (Qabila or the big family) [8].

We have examined demographic characteristics of the patients and the prevalence of familial lupus among first, second, and third degree relatives. We have also compared the percentage of familial versus sporadic form of the disease. Differences in clinical characteristics in familial and sporadic form of the disease were also assessed.

\section{Statistical Analysis}

Collected data were analyzed with the statistical software program IBM SPSS Statistics V.19. A descriptive analysis was carried out by the calculation of mean, median, SD, minimum and maximum, where applicable. We performed two-tailed student $t$ test to compare familial versus sporadic form.

\section{Results}

A total of 47 patients participated in this study. All the patients were female, aged between 18 and 43 years (Table 1). The highest percentage of patients resided in the central region of Saudi Arabia 16 (34\%) at the time of the study, while the lowest number of patients were located in the northern region 3 (6.4\%) (Table 1). The origin of the big family or tribe was also most common in the central region of Saudi Arabia 16 (34\%), while the distribution of patients in other regions was similar (Table 1 ).

The data analysis resulted in 13 (27.7\%) patients with at least one 1st, 2nd, or 3rd degree relative diagnosed with SLE which we assigned to Category A (familial form) (Table 2). Sporadic form of SLE was found in 34 (72.3\%) patients who had no 1st, 2nd, or 3rd degree relatives affected with SLE, assigned to Category B (Table 2). There were 19 (40.4\%) patients with at least one 1st, 2nd, 3rd, 4th, or 5th degree relative diagnosed with SLE

Table 1. Demographic characteristics of the participants.

\begin{tabular}{cc} 
Parameters & Values \\
Total No. & 47 \\
Age ( mean \pm SD) years & $18-43(28.2 \pm 6.03)$ \\
Female sex No. (\%) & $47(100)$ \\
Marital status No. (\%) & $18(38.3)$ \\
Married & $29(61.7)$ \\
Single & \\
Region of origin No. (\%) & $7(14.9)$ \\
West & $7(14.9)$ \\
North & $10(21.3)$ \\
South & $7(14.9)$ \\
East & $16(34)$ \\
Middle & \\
Residence No. (\%) & $13(27.7)$ \\
West & $3(6.4)$ \\
North & $5(10.6)$ \\
South & $10(21.3)$ \\
East & $16(34)$ \\
Middle & \\
\hline
\end{tabular}


Table 2. Distribution of patients with SLE by presence of the disease among family members.

\begin{tabular}{|c|c|c|c|c|c|c|c|}
\hline $\begin{array}{c}\text { Patient } \\
\text { (Serial No.) }\end{array}$ & $\begin{array}{c}\text { Female: male } \\
\text { ratio } \\
\text { (including the } \\
\text { patient) }\end{array}$ & $\begin{array}{l}\text { Total } \\
\text { number of } \\
\text { affected } \\
\text { relatives }\end{array}$ & $\begin{array}{l}\text { First degree } \\
\text { relatives } \\
\text { (No.) }\end{array}$ & $\begin{array}{c}\text { Second } \\
\text { degree } \\
\text { relatives } \\
\text { (No.) }\end{array}$ & $\begin{array}{c}\text { Third } \\
\text { degree } \\
\text { relatives } \\
\text { (No.) }\end{array}$ & $\begin{array}{c}\text { Fourth } \\
\text { degree } \\
\text { relatives } \\
\text { (small family } \\
\text { or Fakith) }\end{array}$ & $\begin{array}{c}\text { Fifth degree } \\
\text { relatives } \\
\text { (big family } \\
\text { or } \\
\text { Qabila) }\end{array}$ \\
\hline \multicolumn{8}{|c|}{ Familial Lupus (Category A) Total = 13 (27.7) } \\
\hline 1 & $2: 1$ & 2 & 2 & & & & \\
\hline 2 & $2: 1$ & 2 & 2 & & & & \\
\hline 3 & $3: 0$ & 2 & 1 & & 1 & & \\
\hline 4 & $3: 0$ & 2 & 1 & & 1 & & \\
\hline 5 & $2: 0$ & 1 & 1 & & & & \\
\hline 6 & 2:0 & 2 & 1 & 1 & & & \\
\hline 7 & $6: 1$ & 6 & & 1 & & 5 & \\
\hline 8 & $3: 0$ & 2 & & 1 & & 1 & \\
\hline 9 & 2:0 & 1 & & 1 & & & \\
\hline 10 & 2:0 & 1 & & 1 & & & \\
\hline 11 & $2: 1$ & 2 & & & 1 & & 1 \\
\hline 12 & 2:0 & 1 & & & 1 & & \\
\hline 13 & 2:0 & 1 & & & 1 & & \\
\hline \multicolumn{8}{|c|}{ Sporadic Lupus ( Category B1 \& B2) Total (\%) = 34 (72.3) } \\
\hline \multicolumn{8}{|c|}{ Participants with distant affected relative(s) who do not meet the familial lupus definition Category (B1) Total (\%) = 6 (12.7) } \\
\hline 1 & 3:0 & 2 & & & & 2 & \\
\hline 2 & 2:0 & 1 & & & & 1 & \\
\hline 3 & $2: 0$ & 1 & & & & 1 & \\
\hline 4 & $2: 0$ & 1 & & & & 1 & \\
\hline 5 & $2: 0$ & 1 & & & & 1 & \\
\hline 6 & $2: 0$ & 1 & & & & 1 & \\
\hline
\end{tabular}

categorized as B1 (Table 2). The number of patients with no relatives affected with SLE (1st, 2nd, 3rd, 4th, or 5th degree) was 28 (59.6\%) and they were assigned to Category B2 (Table 2).

Age of patients was similar in the familial and sporadic groups (28.3 \pm 6.49 vs. $28.1 \pm 5.95$; Table 3). A higher consanguinity level between parents of the patients (1st, 2nd, 3rd, 4th, or 5th degree relatives) was noticed in both familial form (61.5\%), and sporadic form (58.8\%) of the disease (Table 3). In a familial group, patients' parents were 3rd degree relatives in $46.2 \%$ of cases, while the percentage was lower in sporadic group (41.2\%; Table 3). Analysis of distribution of patients with sporadic form by regions of residence resulted in the highest percentage of patients from the central region of Saudi Arabia (35.3\%), followed by the western region (32.4\%) (Figure 1). An equally high percentage of patients with familial form had residence in the east and central region (30.8\%; Figure 1). Patients with the sporadic form had their origins in the tribes predominantly from the central region (35.3\%), while patients with familial form originated mostly from Eastern and central region (30.8\%) (Figure 2).

Systemic involvement of SLE included several different manifestations: musculoskeletal (arthritis and arthralgia), constitutional (fever, weight loss, and fatigue), skin (alopecia, photosensitivity, Raynaud's, urticaria, vasculitis, and purpura), discoid, gastrointestinal (nausea, vomiting, and abdominal pain), renal (proteinuria, haematuria, nephrotic syndrome), haematological (anemia, thrombocytopenia, and leucopenia), cardiac (pericarditis, endocarditis, and myocarditis), CNS (seizures, psychosis, peripheral and cranial neuropathy), and pulmonary (pleurisy, parenchymal disease, pulmonary hypertension) (Table 4). The most common clinical manifestations 
Table 3. Age, marital status, and consanguinity between parents of patients with familial and sporadic form of SLE.

\begin{tabular}{|c|c|c|c|}
\hline \multicolumn{2}{|l|}{ Parameters } & \multicolumn{2}{|c|}{ Values } \\
\hline & & Familial & Sporadic \\
\hline Age $($ mean \pm SD) years & & $28.3 \pm 6.49$ & $28.1 \pm 5.95$ \\
\hline Marital status No. (\%) & & $4.0(30.8)$ & $14.0(41.2)$ \\
\hline \multirow{7}{*}{ Consanguinity between parents No. (\%) } & 1st degree & $0(0)$ & $0(0)$ \\
\hline & 2nd degree & $0(0)$ & $0(0)$ \\
\hline & 3rd degree & $6(46.2)$ & $14(41.2)$ \\
\hline & 4th degree & $1(7.7)$ & $2(5.9)$ \\
\hline & 5th degree & $1(7.7)$ & $4(11.8)$ \\
\hline & Any degree & $8(61.5)$ & $20(58.8)$ \\
\hline & No consanguinity & $5(38.5)$ & $14(41.2)$ \\
\hline
\end{tabular}

Table 4. Clinical characteristics of patients with sporadic and familial form of SLE.

\begin{tabular}{|c|c|c|c|}
\hline \multicolumn{2}{|c|}{ Parameters } & \multicolumn{2}{|c|}{ Values } \\
\hline & & Sporadic & Familial \\
\hline \multirow[t]{10}{*}{ Systemic involvement No. (\%) } & Musculoskeletal* $^{*}$ & $27(79.41)$ & $12(92.31)$ \\
\hline & Constitutional $^{\dagger}$ & $4(11.76)$ & $3(23.08)$ \\
\hline & $\operatorname{Skin}^{\ddagger}$ & $25(73.53)$ & $9(69.23)$ \\
\hline & Discoid & $8(23.53)$ & $2(15.38)$ \\
\hline & Gastrointestinal $^{\S}$ & $3(8.82)$ & $1(7.69)$ \\
\hline & Renal $^{* *}$ & $19(55.88)$ & $8(61.54)$ \\
\hline & Haematological $^{\dagger+}$ & $22(64.71)$ & $9(69.23)$ \\
\hline & Cardiac $^{\ddagger \ddagger}$ & $1(2.94)$ & $1(7.69)$ \\
\hline & $\mathbf{C N S}^{\S \S}$ & $10(29.41)$ & $7(53.85)$ \\
\hline & Pulmonary $^{* * *}$ & $3(8.82)$ & $0(0)$ \\
\hline \multicolumn{2}{|l|}{ Onset age (mean $\pm \mathrm{SD}$ ) years } & $21.6 \pm 5$ & $22.1 \pm 5.95$ \\
\hline \multicolumn{2}{|c|}{ Number of ward admissions (mean \pm SD) $)^{\dagger+\dagger}$} & $1.3 \pm 4.07$ & $0.5 \pm 0.44$ \\
\hline \multicolumn{2}{|c|}{ Number of ICU admissions (mean \pm SD) } & $0.1 \pm 0.35$ & $0 \pm 0.02$ \\
\hline
\end{tabular}

${ }^{*}$ Arthritis and arthralgia; ${ }^{\dagger}$ fever, weight loss, and fatigue; ${ }^{\ddagger}$ alopecia, photosensitivity; Raynaud’s, urticaria, vasculitis, and purpura; ${ }^{\S}$ nausea, vomiting, and abdominal pain; '** proteinuria, haematuria, nephrotic syndrome; ${ }^{\dagger \dagger}$ anemia, thrombocytopenia, leucopenia; ${ }^{\ddagger \neq}$ pericarditis, endocarditis, myocarditis; ${ }_{\S}$ seizures, psychosis, peripheral and cranial neuropathy; ${ }^{* * *}$ pleurisy, parenchymal disease, pulmonary hypertension.

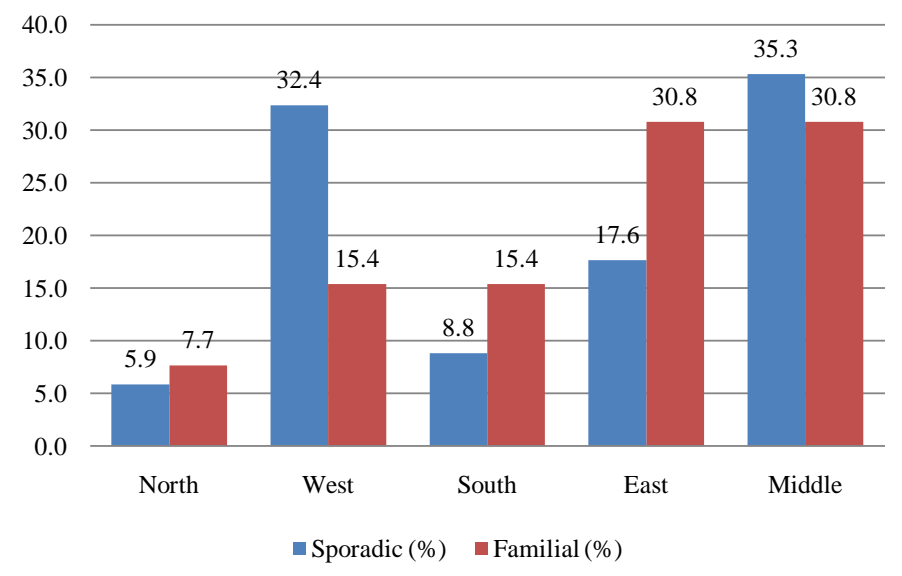

Figure 1. Distribution of familial and sporadic form of SLE by patients’ residence. 


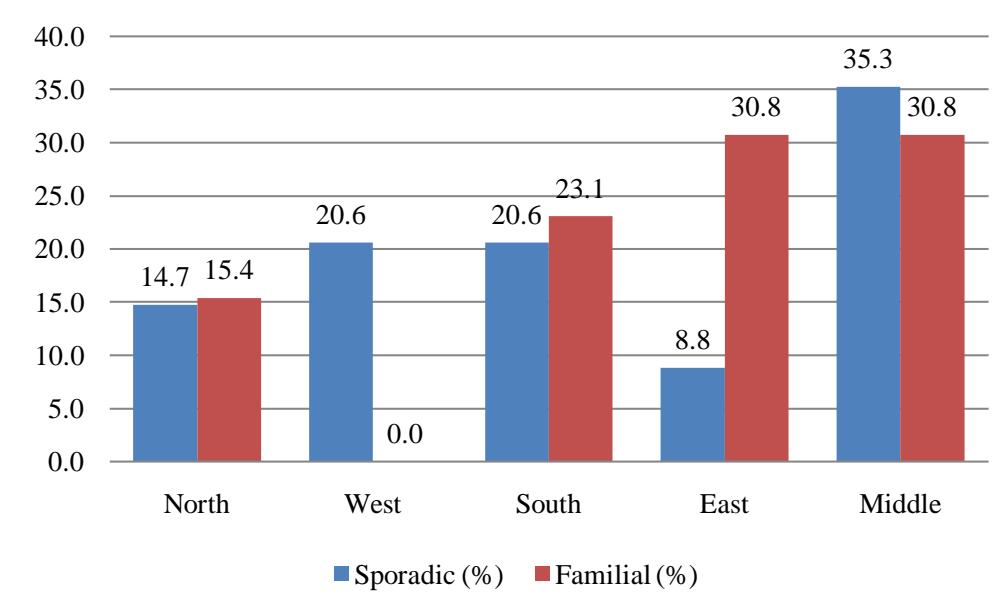

Figure 2. Distribution of familial and sporadic form of SLE by patients' origin.

in patients with both sporadic and familial form were musculoskeletal (S: 79.41\%, F: 92.31\%), skin-related (S: 73.53\%, F: 69.23\%), and hematological (S: 64.71\%, F: 69.23\%) (Table 4). Musculoskeletal, constitutional, ren$\mathrm{al}$, hematological, cardiac, and CNS-related manifestations were more common in familial than in sporadic groups, and there was no pulmonary manifestation in familial group (Table 4). No statistically significant difference was found in clinical manifestations between patients with familial and sporadic forms.

The onset age ranged from 10 to 30 years in the sporadic group (21.6 \pm ), and from 14 to 33 years in familial group (22.1 \pm 5.95$)$ (Table 4). Average number of ward admissions was higher in the sporadic group (1.3 \pm 4.07), compared to the familial group $(0.5 \pm 0.44)$ (Table 4$)$. Also, the average number of ICU admissions was higher in the sporadic group $(0.1 \pm 0.35)$ than in the familial group $(0 \pm 0.02)$ (Table 4$)$.

\section{Discussion}

Research showed that the highest percentage of patients both originated and were resident in the Central region of Saudi Arabia (Table 1). These results remained nearly the same when we compared percentages in familial and sporadic group, with the exceptions regarding residence in the Western region and origin of the patients in the Eastern region. Patients (Figure 1 and Figure 2). To our knowledge, this is the first study showing regional distribution of sporadic and familial lupus in Saudi patients. Differences in regional distribution of familial form of SLE can stem from different consanguinity rates between the regions. Prevalence of consanguinity by region have been investigated by other studies, and the current evidences show the highest overall consanguinity rate of 67.2\% in Medina region, while the lowest consanguinity rate of 42.1\% was noted in Al-Baha region [11].

Since familial SLE is suggested to have an autosomal recessive pattern of inheritance [12], consanguinity is considered a significant risk factor for its development [13]. In our study, overall consanguinity rate between patients' parents was high in both familial and sporadic group (61.5\% vs. 58.8\%; Table 3). These results could suggest that consanguinity may be the cause of higher prevalence of SLE in Saudi Arabia compared with developed countries [3]. In one study from Kuwaiti population [14], which is also considered highly consanguineous, the prevalence of familial SLE was $27.4 \%$, which is almost identical to our results (27.7\%; Table 2).

Although we used the same criteria for familial SLE as other studies, we have also extended the research to distant relatives, and found that 6 patients (12.7\%) had at least one 4th and/or 5th degree relative affected with SLE (Table 2). In relation to this, we found higher percentage of patients' parents being 4th degree relatives in familial group than in sporadic group (7.7\% vs. 5.9\%; Table 3), but the results went in the opposite direction for 5th degree relatives $(7.7 \%$ vs. $11.8 \%$; Table 3$)$. This could mean that the risk of SLE can still be pronounced in consanguinity between 4th degree relatives and that the SLE could be having higher heritable potential than estimated so far. Marriage between 5th degree relatives does not seem to have the potential to increase the risk of familial SLE.

In our study, age of onset was similar in patients with sporadic and familial SLE (21.6 \pm 5 years and $22.1 \pm$ 5.95 years; Table 4), which is in accordance with the results of some other studies [15]. Clinical features of familial and sporadic SLE, including organ involvement, ICU admission rate, and ward admission rate showed similar percentages (Table 4). Similar clinical presentation of familial and sporadic form was confirmed by oth- 
er studies, but they stressed that it varies greatly between different races [16] [17]. As our study included only patients of Saudi nationality, our results are in accordance with the results of other studies.

The result showed high prevalence of familial lupus among Saudi patients. However, the limited number of patients in both groups may be the factor where consanguinity and clinical characteristics comparisons were not entirely representative. Again, using the social media to collect patients may have some bias for sample collection although it may cover more geographic area over the country.

\section{Conclusion}

In summary, our results show that a high percentage of familial lupus in Saudi patients may be a consequence of high consanguinity rate in Saudi Arabia. This study confirms findings of other studies in terms of similar clinical presentation and age of onset in patients with familiar and sporadic form of SLE. More research is required in order to estimate the actual inheritance pattern of familial SLE, as well as involvement of genetic and environmental factors.

\section{References}

[1] Danchenko, N., Satia J, A. and Anthony, M.S. (2006) Epidemiology of Systemic Lupus Erythematosus: A Comparison of Worldwide Disease Burden. Lupus, 15, 308-318. http://dx.doi.org/10.1191/0961203306lu2305xx

[2] Al-Arfaj, A.S., Al-Balla, S.R., Al-Dalaan, A.N., Al-Saleh, S.S., Bahabri, S.A., Mousa, M.M., et al. (2002) Prevalence of Systemic Lupus Erythematosus in Central Saudi Arabia. Saudi Medical Journal, 23, 87-89.

[3] Alballa, S.R. (1995) Systemic Lupus Erythematosus in Saudi Patients. Clinical Rheumatology, 14, 342-346. http://dx.doi.org/10.1007/BF02208351

[4] Al-Nasser, A.A., Aboul-Enein, M.-S. and Al-Aska, A.K. (1988) Systemic Lupus Erythematosus in Riyadh, Saudi Arabia. Journal of the Royal Society of Health, 108, 90-96.

[5] Criswell, L.A. (2008) The Genetic Contribution to Systemic Lupus Erythematosus. Bulletin of the NYU Hospital for Joint Diseases, 66, 176-183.

[6] Priori, R., Medda, E., Conti, F., Cassara, E.A., Danieli, M.G., Gerli, R., et al. (2003) Familial Autoimmunity as a Risk Factor for Systemic Lupus Erythematosus and Vice Versa: A Case-Control Study. Lupus, 12, 735-740. http://dx.doi.org/10.1191/0961203303lu457oa

[7] Duarte, C., Couto, M., Ines, L. and Liang, M.H. (2011) Chapter 36-Epidemiology of Systemic Lupus Erythematosus. In: Lahita, R.G., Ed., Systemic Lupus Erythematosus, 5th Edition, Academic Press, San Diego, 673-696. http://dx.doi.org/10.1016/B978-0-12-374994-9.10036-1

[8] (1992) Saudi Arabia [Electronic Resource]: A Country Study. Federal Research Division, Washington DC.

[9] El-Hazmi, M.A., Al-Swailem, A.R., Warsy, A.S., Al-Swailem, A.M., Sulaimani, R. and Al-Meshari, A.A. (1995) Consanguinity among the Saudi Arabian Population. Journal of Medical Genetics, 32, 623-626. http://dx.doi.org/10.1136/jmg.32.8.623

[10] (NHS) (2015) NGaGEC. First-Degree Relative 2015. http://www.geneticseducation.nhs.uk/genetic-glossary/181-first-degree-relative

[11] El-Mouzan, M.I., Al-Salloum, A.A., Al-Herbish, A.S., Qurachi, M.M. and Al-Omar, A.A. (2007) Regional Variations in the Prevalence of Consanguinity in Saudi Arabia. Saudi Medical Journal, 28, 1881-1884.

[12] Qari, A., Al-Mayouf, S. and Al-Owain, M. (2009) Mode of Inheritance in Systemic Lupus Erythematosus in Saudi Multiplex Families. Genetic Counseling, 20, 215-223.

[13] Eroglu, G.E. and Kohler, P.F. (2002) Familial Systemic Lupus Erythematosus: The Role of Genetic and Environmental Factors. Annals of the Rheumatic Diseases, 61, 29-31. http://dx.doi.org/10.1136/ard.61.1.29

[14] Abutiban, F., Mokkaddam, K., Ameen, E., Moussa, M. and Alsaeid, K. (2009) Comparison between Familial and Sporadic Systemic Lupus Erythematosus in Kuwaiti Patients. Lupus, 18, 86-91. http://dx.doi.org/10.1177/0961203308094228

[15] Koskenmies, S., Widen, E., Kere, J. and Julkunen, H. (2001) Familial Systemic Lupus Erythematosus in Finland. The Journal of Rheumatology, 28, 758-760.

[16] Sestak, A.L., Nath, S.K., Kelly, J.A., Bruner, G.R., James, J.A. and Harley, J.B. (2008) Patients with Familial and Sporadic Onset SLE Have Similar Clinical Profiles But Vary Profoundly by Race. Lupus, 17, 1004-1009. http://dx.doi.org/10.1177/0961203308091969

[17] Abid, N., Khan, A.S. and Al Otaibi, F.H. (2013) Systemic Lupus Erythematosus (SLE) in the Eastern Region of Saudi Arabia. A Comparative Study. Lupus, 22, 1529-1533. http://dx.doi.org/10.1177/0961203313500548 